\title{
EDITORIAL
}

\section{The epistemology of normality ${ }^{1}$}

\author{
'It does not seem a profitable procedure to make odd noises on the offchance that posterity \\ will find a significance to attribute to them' (Eddington, 1928).
}

\section{DETACHMENT AND SYMMETRY}

The more a science deals with humanity, the less highly resolved it is, and the less its truths are susceptible of cogent proof. This principle is, I think, ascribable to Norbert Wiener, although it is difficult to document adequately. Thus, the 'exact' sciences, physics and chemistry, are also the most remote; scientifically, microbial genetics is much more satisfactory than human genetics; and of all topics of human genetics, the most distinctively human, behaviour and psychiatric disease, are in the most parlous state.

It is not difficult to see, in broad terms at least, why this should be so.

(1) Even the most extreme reductionist would agree that the structure and functioning of the human body is vastly more complex than that of the individual atom. Whether there is an ensemble effect, an emergence, ascribable to the complexity of the interactions and to be inferred with difficulty (or perhaps not at all) from the individual properties of the component parts, is a matter well known to the neurophysiologists. But the problem of finding an illuminating conceptualization of the whole pattern is open. The field is still in that somewhat naive state which existed before Mendel and Galton in genetics and Clerk-Maxwell in physics perceived that the joint behaviour of a complex system may follow certain probabilistic patterns which can be conveniently and usefully studied even when no individual component could be scrutinized. The canons of rigour of such a representation certainly exist but are very different in type from those of classical Laplacian physics. The mere fact that no analogous paradigm has yet been found for human behaviour is no reason for assertive nihilism.

(2) There are many constraints on research in man: the relatively long life of the subject compared with that of the investigator; the ethical limitations on manipulation; the constraint of political freedom; the expense of human research; and many more.

(3) More than any other animal, man is self-conscious. The fact of being observed alters behaviour and in man the change may be deliberate or the result of suggestion. Those who do clinical trials are acutely aware of these problems: the need for the double blind, and the problems of maintaining it.

(4) Scientific experimentation on man (as distinct from passive observation) has a shorter history than comparable disciplines.

For these reasons (and doubtless many others) past accomplishments in human biology are meagre; and we look forward to future developments. But it would be foolish to underestimate the dimensions of the ultimate problems. We do not know enough about human biology to warrant any great precision for that statement; but, at least by analogy from other fields, one can see wherein one major problem lies: the difficulty of detachment. I cite analogies from 4 disciplines: physics, mathematics, psychiatry and epistemology.

In physics, the most explicit science of all, relativity theory has abandoned the facile separation of the observer from the observed, as Bronowski (1960) has pointed out. Into any equation for which invariance is to be claimed the observer himself must be incorporated. This involvement is not merely that invoked by pre-Einsteinian physicists to patch up the wounds of Newtonian mechanics, but a fundamental invasion of the sacred detachment of the observer. The observer is merely a part of the whole system, and (in a physical sense) neither a privileged nor a special part.

\footnotetext{
1 Address for correspondence: Dr Edmond A. Murphy, Division of Medical Genetics, Johns Hopkins University School of Medicine, Baltimore, Maryland 21205, USA.
} 
In mathematics even a steady retreat from physical reality, into a pure mathematics which owes allegiance to axiomatics alone, has proved no safeguard. Gödel's incompleteness theorem has shown in some generality that any finite set of axioms must, sooner or later, lead to problems, falling within their compass, to which no unambiguous answers can be given. Always, further axioms are needed. The mathematician is denied economy, his principal aesthetic criterion. Inasmuch as axioms are arbitrary, the mathematician cannot remain uninvolved. He is no more a detached and self-contained observer than the physicist is, but must personally invade his field from time to time.

To the psychiatrist, of course, this pattern of inexorable participation is a commonplace. The psychiatrist is not one class of being, the patient another. Analytical psychiatry has insisted, very rightly, on 2 key principles. First, the resources for solving the patient's problem must ultimately come from within: they cannot be manufactured by the psychiatrist, or quarried from the sacred writings of the masters. The second is the explicit recognition that the psychiatrist's own view of the world is personal, and that to foist it on the patient is prejudice. In the stricter schools, the psychiatrist is required to undergo analysis with the express aim of laying bare his own prejudices and making allowances for them in the interactions with his patients.

The philosopher has, of course, long recognized that, while epistemology cannot be constructed entirely from within the field of its application, neither can it afford to ignore that field. If it is not to be void, epistemology must appeal to empirical fact. Once this appeal is made, the philosopher is bound by the discipline he has embraced. But he remains a philosopher and is not to be treated democratically as merely one voice of no special importance. The impartiality of (say) physics does not lend itself to a theory of values or a quest for ultimate meaning; they can come only from a study of the relationship of physics to other knowledge and insights.

From these 4 examples I draw a general principle of the symmetry of the parts expressed somewhat crudely, as follows. In the domain of natural knowledge (that is, without appealing to revelation, mysticism or other transcendental forms), a priori every part of a system is as good, as important, as significant, as every other part. (I insert the term 'a priori' because, if the symmetry were inalienable, no non-trivial conclusions at all could be reached by argument or by the pursuit of knowledge.) We always suppose that, ultimately, truth is more important than evidence and parity cannot be maintained between them.

I do not claim to have proved this principle of symmetry in general, or even in particular. But reflection on it in the light of the 4 examples persuades me that it is a sounder and safer viewpoint than, say Maritain's (1956) theory of knowledge, that philosophy has a special right to sit in judgement on science, a right which is asymmetrical because it is unreciprocated. If we believe that, in some sense, truth is homogeneous, then philosophy, theology, science and art must be mutually reconciled and reconcilable. Bad philosophy should be subject to condemnation by science, as bad science is condemnable by philosophy.

\section{NORMALITY AND THE MEANING OF MEANING}

It is commonly claimed that medicine is a science which is gaining strength as our understanding and knowledge progress. We are also often reminded that medicine is an 'art', a term used apologetically for jury-rigged solutions to problems, where current science falls short. But sound practitioners know that medicine is a 'full-thickness' slice of life, not merely an academic abstraction of certain points of interest. In the past, medical judgement drew on an education which was presumed to be broad; it could presume a largely unified social conscience; such judgements centred on immediate and urgent problems; and they were severely curtailed by the narrow scope of the possible. All 4 factors have been eroded in recent years: the surrender of at least the ideal of broad education to technical instruction; the half-informed turmoil and polarization of public opinion crudely manipulated by the demagogue; the technical successes which have shifted interest from acute to chronic disease; and the precipitous change in the scope of our diagnosis, prognosis and treatment. A need, and (in lesser degree) a demand, for a philosophy of medicine has surfaced; and despite the energies of a handful of scholars, the hiatus is wide, and growing. The difficulties are twofold. On the one hand, there is a 
shortage of philosophers who are really prepared to study the medical scene and of physicians with even the most rudimentary grasp of the nature and scope of philosophy. On the other hand, there is little recognition that the gap of communication exists: that neither Procrustian formulae a thousand years old, nor naïve common sense is sufficient to meet the need. At best, shallow solutions postpone the day of reckoning; at worst, they obscure, falsify, mislead.

There are a great many notions that have a crude utility which constitute what we call common sense. No doubt it is a good (if somewhat obvious) general principle that tall men should beware of bumping their heads going through doorways. It does not matter that doorways vary in size or that the notion of a 'tall man' is a vague one. The caution embodies, with logical precision, the peril of incompatibility. We might refine it somewhat by saying that the taller a man the fewer doors he can go through without stooping. It is a moot point as to whether any more precise distillation is possible or desirable. One might even say that the strength of the statement lies in its physical vagueness.

However, this is a quantitative age with a widespread implicit belief that 'precision' and 'reproducible measurement' are interchangeable terms. (And indeed 'precision' has come to have exactly that technical meaning in statistics.) Certainly, reproducible measurement is evidence of precision of a kind, although its predicate may be something of trivial import (as for instance the weight of Michaelangelo's David would be). It would be foolish either to suppose no other form of precision possible or that precision is the ineluctable metric of all profound surmise. That useless pain is undesirable and that it is the duty of the medical profession to relieve it are perfectly definite statements which cannot be eroded by the lack of a satisfactory measurement, the semantic problems of defining pain, or the formidable problems of deciding which pains are indeed useless. Nevertheless, this claim is not to say that these terms are not worthy of more profound exploration. Nor, on the other hand, does it mean that our craving for precision should let us settle for some measurement for no better reason than that it is highly reproducible. We have suffered more than enough from the heresies of both vague nihilism and untimely quantitation. Canonizing tentative measurement, especially of that which has not been subjected to profound reflection, is to be condemned. Yet there is a kind of naïve theory among medical scientists (which fortunately the practitioners do not take seriously) which dismisses as 'noise' everything which measurement does not comprise.

For a long time we have glorified 'fitness', 'health', 'normality', as ideals to be pursued by attacking their contraries. As they stand, these goals go scarcely beyond broad sentiment. But (as Adlai Stevenson remarked) slogans are designed to produce action, not thought. It is only from mobilizing concern that we may expect useful progress; but ill-directed motion can have devastating consequences. It is the traditional function of the philosopher, not to produce ideals out of thin air, but to help his fellow men to perceive the implications of their narrow analyses on the one hand and their broad enthusiasms on the other. But (with minor and often ignominious exceptions) the medical profession, for one, has floundered in vain with its weighty problems. A scholar's allegiance is a sacred matter which we cannot attack without imperilling academic freedom. But right and responsibility are inseparable; and whatever the individual philosopher may do, we are surely entitled to vest a corporate responsibility with philosophers to help us with our difficulties. Conversely we would not deny the physician the right to do research in some field perhaps remote from clinical practice; but the philosopher would have a grievance if he could find no physician to look after him when he is sick. A profession can fail as a whole even if no one person can be blamed.

It is not as if the issue is a trivial one. A large part of medical ethics and much of the whole underpinning of current medical policy, private and public, are squarely based on the notion of disease and normality. Left to himself the physician (whether he realizes it or not) can do very well without a formal definition of disease. Despite the clumsy nosology in which textbooks abound, he treats, not technical terms, but patients. The notorious debate about the nature of essential hypertension passes him by: what he does to patients is dictated by what the patient's state and needs are. Insofar as he makes any decision on the basis of blood pressure, he considers what the blood pressure reading actually is, not what it is called. Superficial thinkers mistake this policy for nominalism, supposing erroneously that the only form of scientific reduction is categorical. This naive belief ignores everything in scientific and mathematical development since Descartes' fundamental work on 
continuous mathematical functions. The confusion of dimensionality with cardinality (Murphy, 1976 ) is a consequence of decadent neo-Aristotelianism from which medicine still suffers (Whitehead, 1925).

Unfortunately, the physician is not left alone to work his common sense. $\mathrm{He}$ is attacked from 2 angles: the predatory consumers and the pretentious advisors.

The predatory consumers are those who demand of him not merely a precisely reasoned answer to their questions (even their meaningless questions) but reserve the right to cross-question him, condemn his diffidence, and threaten him with malpractice. He will be expected to apply (with spurious exactitude) laws about mental deficiency which, by their very nature, can embody nothing more than broad sentiment. He is required to provide often meaningless detail on death certificates (from which in due course specious vital statistics will be compiled). He cannot give patients what he deems warranted reassurance but, in an increasing mania for disclosure (especially in the United States), must furnish, out of context, whatever raw data the patient demands. Whole areas of legislation on the pursuit, elucidation and prevention of disease are consigned to him for execution, however ill-considered, ambiguous or fanciful.

On the other hand, and much more damagingly, he is the victim of his advisors who more and more worship false gods. They suppose that measurement is always better than non-measurement. They do not grasp that there are hierarchies of precision and that, while they may have solved the purely metrical aspect of a subject, they have before them as great a task or greater in infusing precision into the meaning of the answer. A commonplace, if superficial, illustration is the investigator who will calculate a chi-square test to 4 significant figures, consult a set of tables with scrupulous attention to degrees of freedom, and publish a probability value; and then in his explanatory comments make it clear that he has a completely mistaken notion what the answer is the probability of. But this is a trivial illustration, 'pure ignorance', which could have been put right with a little more instruction. The real difficulties lie in those cases where no adequate interpretation of the highly precise measurement has been proposed, where there is even no assurance that it has any non-trivial meaning. This gap is rarely met by an honest avowal of ignorance or incompetence. Instead it is carelessly overlooked, glossed over, or handled with a little hasty addendum.

An admirable example is the XYY karyotype. The cytological aspects of this interesting condition were handled faultlessly. How the interpretation was handled is a standing disgrace to both medicine and the law. There was much more to these lapses than mere ignorance of the elementary techniques of inference (although one might have supposed that any scientist would know that one cannot do tests of association between karyotype and phenotype without serious attention to definition of the reference population and the sampling procedure). What is appalling is that the fruit of this insouciance has so much power to affect human lives: the suspicion it engenders; the false importance ascribed to it in legal defence; even, by implication, one more shallow attack on personal responsibility and freedom. There have been heroic, but not altogether successful, attempts to remedy, after the event, the lack of sound empirical information on the relationships between karyotype and phenotype (Borgaonkar \& Shah, 1974; Hook, 1973; Hamerton, 1976). But they have been constrained by an atmosphere already biased and emotionally charged with militant concern for human freedom, which has hampered the collection of the facts necessary to clarify the issue.

However, let us suppose that the empirical evidence of the relationships were sound, that those with the XYY karyotype were convicted more often of crimes of violence; and, for simplicity, we will further suppose that the association is not due to more efficient policing (because of conspicuous height) or prejudice of juries against men with acne. What are we to make of the meaning of such an empirical association? There have been attempts to use the karyotype, as insanity is used, as a legal defence. But clearly empirical association is an insufficient argument. No doubt but that rape is much more commonly committed by men than by women: but, even in the midst of a furore against sexual discrimination, nobody would argue that possession of a Y chromosome is a defence against a charge of rape or any other crime to which adult males are disposed. Besides, no evidence whatsoever has been adduced that all XYY subjects commit acts of aggression; hence it is difficult to argue (in any deterministic sense) that this karyotype causes such crimes. Confused as the legal practice is on 
the use of insanity as a defence, it has never to my knowledge been ruled-even in the extreme Durham opinion (1954) - that no insane person can ever be found legally guilty of a crime.

What keeps it from being dismissed out of hand is an implicit appeal to normality. The principle would be somewhat as follows. Where a condition is so abnormal as to impose an extraordinary burden on the patient, we may invoke it as a defence. The law does not state it so; indeed, I have had the greatest difficulty in finding the word 'normal' used in any legal ruling; but without its unseen presence, any legal principle of defence for medical reasons would flounder. Acute alcoholism is as rational a defence as insanity. The main difference lies in the fact that acute alcoholism must be presumed culpable. But leaving this aspect aside, all the legal psychiatric principles of defence nature-and-quality, uncontrollable impulse, product-disease - apply to drunkenness, as well as to schizophrenia.

\section{THE DELIMITATION OF NORMALITY}

Two of the main 'consumers' of the physician's opinions about normality, the surgeon and the criminal lawyer, have in common the need for a sharp endpoint. The patient is either operated on or not. The prisoner is either convicted or not. The details may modify the extent of the operation or mitigate the severity of the sentence, but there is no such outcome as being slightly operated on, or moderately convicted. Hence 3 questions arise:

(1) Do multiple states exist?

(2) How are they best distinguished?

(3) Which of them are to be designated abnormal?

In some very few areas the first 2 questions are easily dealt with. Sickle cell disease is clearly demonstrated at a chemical level, the most highly resolved we have. Precise distinction between it and the wild-type trait is available. Galactosaemia and haemophilia undoubtedly exist; diagnosis is almost foolproof, and reasonable criteria for resolving diagnostic (as distinct from ontological) doubt exist. In a great many cases - hypertension, diabetes, obesity - the answers to both questions are doubtful; but at least precise and well-established measurements provide data for speculation.

In some cases, most notably in disorders of behaviour, intellect and emotion, no such well-tried scales exist, although arbitrary scales have been devised. Now, of course, in the ultimate economy of things, these arbitrary scales are not necessarily inferior to the centimetre-gram-second scale of the physicist. Doubtless the measurements are more subject to spontaneous variation or observer error; but no scientist refuses to use the cgs scale in biochemistry on grounds of variance. The issue is not mainly the statistical but the epistemological properties of these scales of measurement. It is not at all easy to see wherein the difference lies except the ineluctably reflexive character of psychiatric scales of behaviour. Theoretically the problem could be approached by techniques of cluster analysis. There are, of course, well-known statistical problems in cluster analysis. The main epistemological difficulty is that the very choice of raw data introduces a bias which no system of scaling can correct a posteriori. (Some of the data may be discarded; but missing data cannot usually be recovered.)

In a trivial sense, of course, wherever there is variation in the characteristics, one can classify. One may divide patients into introverts and extroverts by some arbitrary point on an arbitrary scale. Invariance of order of magnitude may still be preserved even if absolute magnitude is not. But a classification in the face of a measurement seems to have warrant only if the classification transcends the measurement: if beneath the 'noise' of the measurement there is some significant state which is the real object of our enquiries. For instance, the valency of an element must be a whole number. If an experimental measurement gave the value $2 \cdot 1$, there is little doubt that ' 2 ' is a better estimate of the true value than ' $2 \cdot 1$ ' (which would be meaningless). In contrast, it seems doubtful that to say a man of 30 exhibits 'tallness' is ever a better estimate of any significant state than his actual height. In practice, it is by no means easy to identify how far the problem is one of discrimination (question 2) and how far it is to identify groups (question 1).

We have not entirely explicated the word 'significant' in the previous paragraph. What may be a scientifically significant grouping is not necessarily clinically significant: the $\mathrm{Xg}(\mathrm{a})$ blood type being a 
good example. Detailed analysis of an unselected population would doubtless turn up innocent haemoglobinopathies which might be of considerable interest to a geneticist. In such cases, the third question - which states are to be designated abnormal - is the point of dispute. Sometimes it is answered very easily: the state of one or more of the groups being grossly disruptive and leading perhaps to rapid death; or alternatively, the distinguishing characters of the groups may be subtle and the phenotypic differences slight or absent, so that by no contortions can it be regarded as an abnormal state. But the dictum 'hard cases make bad law' is readily reinterpreted to our purpose: a principle founded on these open-and-shut examples would be useless in many, perhaps most, adjudications. The more a conclusion is said to be 'obvious', the more we should have our suspicions awakened that the issue is being not solved, but evaded. It may be 'obvious' to a fashion designer whether a woman's hair is or is not red; there is much (probably unfounded) popular psychology about such people; admirers of Titian may discuss its aesthetic properties; but the evidence we have is that, scientifically, there is no such category as redheadedness (Reed, 1952). But, after all, it is rarely a hanging matter whether a person's hair is red or not: if Sherlock Holmes had been as astute as Watson thought he was, he would have seen through the story of the red-headed league (Doyle, 1930) from the start as something which could not be defined legally. Yet, wherever due legal process is denied, there is a tendency to pass laws which for lack of sound criteria cannot be applied except by abuse. A professional geneticist has the greatest difficulty over the notion of race. So far as one can define by gene frequencies, it has been established repeatedly that, on average, the so-called American Negro derives $30 \%$ of his genes from 'White' North European ancestors; and this must mean that, by random variation, in many the proportions must be $50 \%$ or over. If race has any meaning other than social, such people are White not Negro; for, if those with any genes which may be of Negro origin are to be called Negroes, almost the entire American population would fall into this group.

It is interesting to note that while, by the content of their field, psychiatrists are the least well equipped to confront the issue of defining normality, they are the only group of clinicians who have taken these problems with anything like the seriousness they merit. Many of these writings are penetrating (Cantor, 1941; Hacker, 1945; Reider, 1950; Offer \& Sabshin, 1966; Sabshin, 1967). Some are radical, and that of Freides (1960) concisely and articulately makes a case for discarding the notion of normality as unworkable. It is perhaps even more remarkable that philosophers in their rare discussions on the idea of normality choose with a kind of perverseness this least well-defined of all fields of clinical medicine.

\section{IMPLICATIONS}

How far should it be the responsibility of the medical profession to become involved in these intricate issues? At first sight it might appear that lacking any formal training in the analysis of values the physician as a professional man had best leave the matter alone. There seem to be at least 4 reasons why this detachment is not to be recommended in practice.

First, the physician does have to make actual decisions. Doubtless it would be best if in seeking values he could appeal to a consensus; but the latter does not exist, and the views of the self-appointed spokesman must not be mistaken for it.

Secondly, supposed views of physicians and the supposed conclusions of medical science are commonly misrepresented, even by scholars from other fields, and such errors must be unmasked. It would be a distasteful exercise to list instances in the writings of distinguished philosophers, theologians, educationalists, politicians' and even physicians themselves where totally unwarranted statements about what 'medical science has shown' are used as the bedrock of weighty discussions: as that emotional structure and behavioural disorders are inherited; that statistics has shown how the normal is to be defined; that the Kinsey reports have shown that such and such practices are not abnormal (despite the most explicit statement from the authors that they were attempting to make no normative inferences). Such statements can be authoritatively condemned only by those prepared and disposed to analyse the issues.

Thirdly, the physician, for all his limitations, is usually at least as well informed on the issues of 
normality and disease as the layman or most experts from other fields. One might wish that he had as much cultivated detachment, and as much insight into his own prejudices, as the psychiatrist. But an imperfect understanding of the implication of facts seems clearly better than an imperfect understanding of gossip or of nothing at all.

Finally, much as we may dislike the idea, patients expect their physicians to have views which they are ready to express. Many of us involved in genetic counselling set a goal of communicating fact and perspective, with compassion and concern, but in strictly non-directive fashion. But parents do not readily embrace the responsibility of making decisions; and if they must have prefabricated ideas they might as well come from the physician as from their neighbours (who are rarely so diffident about directiveness).

EDMOND A. MURPHY

The work in this paper is supported by NIH Grant No. GM 24736.

\section{REFERENCES}

Borgaonkar, D. S. \& Shah, S. A. (1974). The XYY chromosome male or syndrome. Progress in Medical Genetics 10 , 135-222.

Bronowski, J. (1960). The Common Sense of Science. Penguin: Harmondsworth.

Cantor, N. (1941). What is a normal mind ? American Journal of Orthopsychiatry 15, 47-64.

Doyle, A.C. (1930). The Red-Headed League. In The Adventures of Sherlock Holmes. Harper and Row: New York.

Durham v. The United States (1954). 214: F 2nd 862-876.

Eddington, H. S. (1928). The Nature of the Physical World, p. 21. Cambridge University Press: London.

Freides, D. (1960). Towards the elimination of the concept of normality. Journal of Consulting Psychology 24, 128-133.

Hacker, F.J. (1945). The concept of normality and its practical significance. American Journal of Orthopsychiatry $15,47-64$.
Hamerton, J. L. (1976). Human population genetics: dilemmas and problems. American Journal of Human Genetics 22, 107-122.

Hook, E. B. (1973). Behavioural implications of the human XYY genotype. Science 179, 139-150.

Maritain, J. (1956). General Introduction to Philosophy. New York.

Murphy, E. A. (1976). The Logic of Medicine. Johns Hopkins University Press: Baltimore.

Offer, D. \& Sabshin, M. (1966). Normality: Theoretical and Clinical Concepts of Mental Health. Basic Books: New York.

Reed, T. E. (1952). Red hair colour as a genetical character. Annals of Eugenics 17, 115-139.

Reider, N. (1950). The concept of normality. Psychoanalytical Quarterly 19, 43-51.

Sabshin, M. (1967). Psychiatric perspectives on normality. Archives of General Psychiatry 17, 258-264.

Whitehead, A. N. (1925). Science and the Modern World. Macmillan: New York. 